\title{
A CONTRIBUIÇÃO DO ESTÁGIO SUPERVISIONADO NA FORMAÇÃO DE ADMINISTRADORES
}

\section{THE CONTRIBUTION OF THE SUPERVISED INTERNSHIP IN THE FORMATION OF ADMINISTRATORS}

\author{
Fernanda Silva Santana \\ Bacharel em Administração, Universidade Federal de Mato Grosso - Campus Universitário de Rondonópolis. \\ Rondonópolis, MT, Brasil \\ E-mail: fhernanda_nanda28@hotmail.com \\ André Luís Janzkovski Cardoso \\ Professor Efetivo da Universidade Federal de Mato Grosso - Campus Universitário de Rondonópolis - Curso de Administração desde \\ 2013. Coordenador da Linha de Pesquisa em Gestão de Pessoas. \\ Rondonópolis, MT, Brasil \\ E-mail: cardoso9778@gmail.com
}

\section{RESUMO}

Este trabalho tem como objetivo analisar o estágio curricular obrigatório supervisionado, considerando que é um curso de Administração na Universidade Federal de Mato Grosso (UFMT-CUR). Analisou-se a percepção dos alunos e ex-alunos sobre a contribuição do estágio na qualificação profissional. $\mathrm{O}$ estudo foi orientado sobre o histórico da lei brasileira, e estudos anteriores. A pesquisa baseou-se em procedimentos técnicos de métodos quantitativos e qualitativos, conduzidos por técnicas estatísticas, e uma análise de categorias, respectivamente. Os resultados não mostraram diferenças estatisticamente significativas entre as percepções dos alunos sobre 0 estágio $e$ as variáveis demográficas. Além disso, apontaram algumas dificuldades vistas pelos alunos, especialmente relacionadas às parcerias entre a universidade e as empresas, eo apoio no processo de orientação. O trabalho apresenta contribuições teóricas e práticas, com discussões para ampliar o conhecimento científico, e porque os resultados podem contribuir com o curso de administração da UFMT-CUR, que está adotando um novo Projeto Pedagógico.

Palavras-chave: Estágio Supervisionado. Formação Profissional. Administração. Ensino Superior. Futuros Profissionais.

\begin{abstract}
This paper aims to analyze the mandatory curricular supervised internship, considering it's a subject in Administration course in Mato Grosso Federal University (UFMT-CUR). It was analyzed the students and ex-students perception about the internship's contribution on the professional qualification. The study was guided on Brazilian law's historical, and previous studies. The research was based on technical procedures of quantitative and qualitative methods, conducted by statistical techniques, and an analysis of categories, respectively. The results showed no differences statistically significant between the students' perceptions about the internship and the demographic variables. Besides, they pointed some difficulties seen by the students, specially related to partnerships between the university and companies, and the support in the orientation process. The paper presents theoretical and practical contributions, with discussions to enlarge scientific knowledge, and because the results can contribute with the administration course from UFMT-CUR, which is adopting a new Course Pedagogical Project.
\end{abstract}

Keywords: Supervised Internship. Professional qualification. Management. Higher education. Future Professionals.

Data de submissão: 10 de fevereiro de 2017.

Data de aprovação: 2 de novembro de 2017 


\section{INTRODUÇÃO}

O estágio supervisionado curricular é uma atividade complementar que tem como intuito transformar a teoria absorvida pelo aluno dentro do âmbito acadêmico em ações práticas nas organizações.

Lourenço, Lemos e Junior (2012) indicam que o estágio curricular supervisionado obrigatório consta em diversos projetos pedagógicos no curso de graduação em Administração no Brasil. Nesse sentido, o estágio deve ser vinculado à formação do futuro bacharel em administração, como é enfatizado por alguns autores (FESTINALLI; CANOPF; BERTUOL, 2007; MICHELS, 2012; ALMEIDA; LAGEMANN; SOUSA, 2006) de forma a realçar a sua relevância e importância na formação acadêmica dos futuros profissionais, sendo necessário o desenvolvimento de estágios curriculares que ultrapassem a simples formalidade, contribuindo para uma formação mais sólida e mais completa (MAÇANEIRO, 2004).

Por outro lado, há também algumas discussões e questionamentos sobre o estágio supervisionado e seu valor para a formação do futuro administrador (ROESCH, 1999; NICOLI, 2003), que muitas vezes tem se tornado uma formalidade para cumprir determinações legais acerca de uma atividade que tem por objetivo permitir ao aluno um contato com a realidade das organizações.

Neste artigo, propõem-se compreender a contribuição do estágio para a formação dos futuros profissionais em administração sobre a seguinte problemática: Qual a percepção dos alunos e ex-alunos do curso de Administração da UFMT - CUR sobre a contribuição do estágio supervisado curricular obrigatório na formação profissional?

Dessa forma, faz-se necessário conhecer as percepções e desafios encontrados pelos alunos que passaram ou estão passando pelo processo do estágio supervisionado curricular obrigatório na UFMT - CUR, levando em consideração que "alunos de graduação em Administração tem se preocupado cada vez mais em complementar a formação acadêmica e adquirir experiência profissional" (MELLO e CASTRO; NICHIMURA; SILVA; CASADO; MADUREIRA, 2007, p. 63).

O objetivo geral da pesquisa é analisar a percepção dos alunos e ex-alunos do curso de Administração da UFMT - CUR sobre a contribuição do estágio supervisionado curricular obrigatório na formação profissional. Esse objetivo se desdobra nos seguintes objetivos específicos:

- Comparar os gêneros e as percepções;

- $\quad$ Comparar os semestres e as percepções;

- Comparar as etapas do estágio e as percepções;

- Comparar os períodos do estudo e as percepções;

- Investigar as contribuições do estágio para os alunos e ex-alunos.

Para isso foram lançadas as seguintes hipóteses:

- $\quad H 1$ : há diferença entre as percepções de acordo com os gêneros;

- $\quad H 2$ : há diferença entre as percepções dos alunos e os semestres que estão cursando;

- $\quad H 3$ : há diferença entre as percepções e as etapas do estágio;

- H4: há diferença entre as percepções e os períodos do dia;

- H5: há diferença entre as percepções dos alunos e ex-alunos sobre o estágio.

Tendo em vista que o estágio curricular supervisionado é uma disciplina obrigatória do curso de graduação de Administração, faz-se necessário realizar uma pesquisa para saber as percepções e os 
desafios encontrados durante o estágio sobre a ótica dos alunos e ex-alunos do curso, os maiores envolvidos nesse processo.

\section{REFERENCIAL TEÓRICO}

\section{Histórico da legislação brasileira sobre o estágio supervisionado curricular}

A origem e a evolução do estágio na legislação brasileira estão ligadas ao avanço educacional do país. De acordo com Colombo e Ballão (2014, p. 174), "desde a década de 1940, diversas normas legais buscaram regulamentar o estágio no Brasil". A primeira legislação que buscou a regulamentação do estágio data de 1942 com o Decreto-Lei n 4.073 que instituía a Lei Orgânica do Ensino Industrial que "estabelece as bases de organização e de regime do ensino industrial, que é ramo de ensino, de segundo grau [...]" (BRASIL, 1942).

Ainda sobre o histórico da legislação os autores complementam que "o estágio escolar somente foi instituído nas faculdades e escolas técnicas no final da década de 60, quando em 1967, sob a ditadura militar, o Ministério do Trabalho e Previdência Social sancionou a Portaria n 1.002" (COLOMBO; BALLÃO, 2014, p. 174). "Entre 1970 a 1975, foram sancionados outros documentos para a regulamentação do estágio em condições específicas" (IEL, 2010, p. 18).

Entretanto, o estágio para ensino de estudantes de estabelecimentos de ensino superior e de $2^{\circ} \mathrm{grau}$ regular e supletivo é objeto da Lei de $\mathrm{n}^{\circ} 6.494$ de 7 de setembro de 1977 e regulamentado pelo Decreto de nº 87.497 em 18 de agosto de 1982.

Contudo, no transcorrer do tempo e diante da necessidade de nova legislação e em decorrência do novo cenário educacional brasileiro, foi sancionada, em 25 de setembro de 2008, a nova Lei de Estágio de $\mathrm{n}^{\circ}$ 11.788, publicada no Diário Oficial da União (DOU) que vigora até os dias atuais. Conforme Michels (2012, p. 45), "o estágio passa a ser regulamentado por um instrumento sistemático que prevê o desenvolvimento da prática alinhada ao currículo e à essência de cada curso de graduação, sempre na observância do desenvolvimento das competências elencadas no perfil do egresso delimitado pela instituição".

Assim, essa lei surgiu de forma mais abrangente e rigorosa, prevendo grandes mudanças, entre elas está o tratamento diferenciado do estagiário dentro da empresa, ou seja, o aluno-estagiário não pode ser considerado como empregado efetivo, além disso, fica explícito novamente na lei que o estágio é um ato educativo supervisionado, portanto é de responsabilidade da instituição de ensino o acompanhamento efetivo pelo professor orientador da instituição de ensino e por supervisor da parte concedente [grifo nosso] (BRASIL, 2008).

A Lei 11.788, também definiu a modalidade do estágio em duas vertentes: o estágio obrigatório e o não obrigatório que é definido conforme a determinação das diretrizes curriculares e do projeto pedagógico de curso. Dessa forma, a presença do estágio obrigatório na grade curricular do curso de Administração aponta para o fato dele poder contribuir de alguma forma para a formação dos futuros profissionais

No entanto, ainda há algumas discussões acerca dessa obrigatoriedade do estágio na formação dos futuros bacharéis de administração, considerando tanto os seus objetivos quanto os desafios encontrados na realidade. Dessa maneira, os instrumentos regulatórios que regem o estágio, como leis, decretos, portarias e 
pareceres, não foram suficientes para que este, na prática, fosse considerado um elemento de formação para os estudantes, pois o papel do estágio supervisionado suscita a análise de outros pontos que também são relevantes para a sua operacionalização, entre eles a sua obrigatoriedade.

\section{Objetivos do estágio supervisionado curricular obrigatório para a formação do profissional em administração}

O estudo acerca dos objetivos que norteiam o estágio supervisionado curricular na formação do profissional em Administração tem sido abordado por diversos autores, que de maneira geral, defendem o relacionamento da teoria com a prática e essa interação dos três agentes, sendo a universidade como agente coordenadora, a empresa como campo e o aluno como sujeito no processo. É esperado que por meio do estágio todos os agentes cumpram o seu papel de forma a contribuir para a formação dos futuros administradores, proporcionando ao estagiário a iniciação da sua futura carreira.

Portanto, o estágio se destaca por ter em uma das suas principais finalidades o primeiro contato dos estudantes com o mundo organizacional, além de ser um meio de suporte para o início de suas carreiras, aumentando suas oportunidades de empregabilidade e experiência.

Como afirmam Mintzberg e Gosling (2003, p. 31) "administradores não podem ser criados em salas de aula, pois a educação gerencial requer a experiência prática". Portanto, o intuito do curso de Administração é o desenvolvimento de profissionais com visão gerencial e estratégica.

Festinalli, Canopf e Bertuol (2007, p. 304) sustentam essa afirmação sinalizando que "no caso da formação do profissional em Administração, o acadêmico poderia adquirir as habilidades da prática profissional estando presente nas organizações de negócios para observar, compreender e adotar as práticas avaliadas como eficazes e utilizadas pelos administradores experientes". Da mesma forma, Michels (2012, p. 44) argumenta que "o estágio em ciências sociais aplicadas e, especificamente, no curso de Administração, remonta à necessidade da sistematização de conhecimentos envoltos na prática e que podem ser reaplicados ou adaptados de acordo com novas insurgências ou necessidades do contexto".

Assim, pode-se inferir que os principais objetivos de um estágio supervisionado para alunos do curso de Administração seja o de aproximar o futuro bacharel da sua realidade, tornando-se alternativa de aprendizagem organizacional, promovendo o desenvolvimento do conhecimento, de técnicas e habilidades do futuro profissional, funcionalidades estas que podem conduzir ao posicionamento desse venturo administrador frente ao mercado de trabalho.

Contudo, para atingir esses objetivos, não se devem desconsiderar os desafios do Estágio para a formação do Administrador. 
Desafios do estágio supervisionado curricular obrigatório para a formação do profissional em administração

O aspecto do estágio em administração em proporcionar ao acadêmico um contato concreto com a realidade organizacional vem promovendo algumas reflexões sobre seu real valor para a formação do futuro administrador, pois apesar da atividade de estágio ser considerada um elo entre a teoria e a prática, ainda há várias críticas nos discursos de professores orientadores de estágio, de supervisores de estagiário nas organizações e por parte dos próprios estudantes. Entretanto, cabe ressaltar que as discussões que tratam das diferenças de percepções sobre o estágio entre universidades, empresas e estudantes não são recentes e tem sido debatida desde o surgimento de cada nova legislação. Conforme apresenta Aquino e Tomassini (2008, p. 1), "tão antiga quanto esta técnica é a polêmica sobre sua validade ou ao menos a respeito da forma com que é de fato aplicada".

Sobre isso, Almeida, Lagemann e Sousa (2006, p. 1) relatam que "o estágio é uma prática obrigatória nos currículos de Administração, [mas] a percepção de sua efetividade torna-se importante na discussão sobre sua essencialidade e reais contribuições para a carreira do administrador". Festinalli, Canopf e Bertuol (2007, p. 306) também consideram que, "a discussão do papel do estágio supervisionado na formação do profissional de Administração suscita a análise de outros aspectos relevantes para sua operacionalização".

A experiência do estágio é fundamental para a formação profissional do administrador, contudo sua implementação dentro da estrutura universitária é um processo difícil, pois são observados alguns obstáculos como deficiência de intermediação de estágios pela faculdade, a falta de integração entre universidades e organizações, a falta de integração do estágio na estrutura curricular, e deficiências da infraestrutura da universidade para apoiar os projetos. Além disto, é notável que alunos tenham dificuldades de escolher tema para o seu projeto, além de enfrentarem problemas para conseguir acesso à organização e problemas de relacionamento com professores orientadores, apontando ausência de metodologia de trabalho $(\mathrm{ROESCH}$, 1999, pp. 19-20).

Seguindo este raciocínio Frey e Frey (2002) descrevem sobre estas dificuldades encontradas no estágio supervisionado, que segundo eles a principal é o acesso do aluno ao estágio nas organizações, pois muitos duvidam da contribuição do aluno neste processo e, portanto, receiam repassar informações e até mesmo restringem, dificultando assim o desenvolvimento do estagiário.

Por fim, é possível indicar que o estágio supervisionado curricular obrigatório possui várias peculiaridades e dependendo da ótica de quem discuta o assunto, pode-se salientar aspectos positivos e negativos. O tópico a seguir indica alguns estudos sobre o Estágio Obrigatório.

\section{Estudos sobre estágio supervisionado curricular obrigatório}

O estudo de Lourenço, Lemos e Junior (2012) sobre o tema "Desafios e Possibilidades no Estágio Supervisionado Obrigatório: A visão dos estudantes do curso de administração" teve como objetivo analisar o processo de desenvolvimento de tais estágios, no Curso de Administração de uma Instituição de Ensino Superior (IES), na visão dos estudantes que já o completaram. Os autores utilizaram de um questionário enviado por e-mail aos estudantes, aplicando um tratamento estatístico às informações coletadas. Os resultados mostraram a burocracia e o processo de orientação como as principais dificuldades. Quanto às 
dificuldades encontradas nas organizações concedentes dos estágios, ressaltaram a falta de supervisão na empresa e dificuldades em conciliar os estudos com o estágio. As oportunidades encontradas no decorrer do estágio compreenderam a obtenção de conhecimento global acerca da organização e o estímulo à criatividade, à inovação e às habilidades de comunicação.

Murari e Helal (2009) procuraram analisar como a prática do estágio se relaciona com a formação de competências profissionais de alunos do curso de Administração de uma IES privada. Para a realização do levantamento da literatura foram utilizadas as bases de dados de revistas científicas brasileiras da área de administração, além dos anais dos congressos organizados pela ANPAD. A partir dos resultados, os autores concluíram que o estágio, em Administração, é um mecanismo que permite a formação de competências profissionais, e contribui de maneira significativa para a inserção do aluno no mercado de trabalho.

No estudo de Festinalli, Canopf e Bertuol (2007), cujo tema era o "Estágio Supervisionado em Administração: reflexões de sua contribuição para a formação profissional", os autores ampliaram a discussão por meio de pesquisa de campo com estagiários do curso de administração de duas instituições de ensino superior da Região Sudoeste do Paraná, sendo uma universidade pública federal e outra privada. Os resultados demonstraram que o estágio supervisionado, independente da instituição ser pública ou privada, contribui para a formação profissional, corroborando com a discussão feita pelos autores consultados sobre o tema, bem como, com a legislação que instituiu a obrigatoriedade do estágio.

Já em Mello e Castro el al. (2007), os autores tratam a respeito da expectativa e satisfação dos alunos de graduação em administração da FEA-USP em relação aos estágios. Os autores levantaram a opinião dos estagiários sobre as oportunidades de desenvolvimento oferecidas pelas empresas e, por meio disso, identificaram as expectativas e necessidades que os motivavam a buscar esses programas e como esses aspectos estavam sendo satisfeitos. Utilizaram-se de um estudo com método qualitativo, de natureza exploratória, cuja unidade de análise foi o indivíduo e não a organização, tendo a coleta de dados por meio de análise de documentos obtidos no banco de dados da Seção de Estágios da FEA-USP e de questionários aplicados aos alunos matriculados na matéria estágio supervisionado. Assim como nos outros artigos, os resultados apontaram que os alunos esperavam, entre outros aspectos, que o estágio fosse uma oportunidade de aplicar, na realidade empresarial, os conhecimentos adquiridos na faculdade e, dessa forma, que ele possibilitasse o crescimento profissional do estagiário e, consequentemente, a obtenção de reconhecimento interno e externo à empresa.

O estudo de Almeida, Lagemann e Sousa (2006) teve como objetivo avaliar a importância do estágio supervisionado para a formação do administrador na contribuição ao desenvolvimento de habilidades e competências, conforme a legislação do Conselho Nacional de Educação. A pesquisa foi realizada com a aplicação de 78 questionários, com um nível de significância de 95\%. Para proporcionar a fidedignidade ao método e estabelecer as correlações foram adotados os parâmetros Qui-Quadrado (X2) e análise de resíduos. Almeida, Lagemann e Sousa (2006) apontam as análises dos resultados, concluindo que a prática do Estágio Supervisionado fornece contribuições significativas para o desenvolvimento de habilidades e competências do administrador.

De autoria de Nascimento e Teodósio (2005) o artigo, "O estágio diante dos desafios do ensino em administração: um estudo de caso sobre as percepções de alunos e supervisores", discute o desenvolvimento de habilidades, posturas e competências profissionais a partir da experiência de estágio no curso de 
graduação em Administração de Empresas. Inicialmente, os autores discutem a evolução das propostas pedagógicas de ensino superior no país, apontando seus desafios e dilemas. A seguir, analisam o papel do estágio nas políticas pedagógicas de graduação em Administração e a evolução desse conceito à luz das políticas educacionais brasileiras. Posteriormente, são discutidos dados resultantes de pesquisa junto a graduandos em Administração que se encontram no período de estágio e seus supervisores em organizações privadas, públicas e não-governamentais.

A pesquisa insere-se no campo do chamado estudo de caso, tendo como foco um curso de graduação em Administração que adotou estratégias modernizadoras de sua proposta didático-pedagógica. Os dados foram coletados por meio da inserção cotidiana dos pesquisadores em sua atividade docente e também com questionários aplicados a professores, alunos e supervisores de estágio em empresas, somados à análise documental. Os resultados apontam convergências e divergências significativas entre as percepções de estudantes e supervisores, possibilitando um avanço na compreensão dos dilemas, perspectivas e possibilidades para ampliação do desenvolvimento de habilidades profissionais na área de Administração a partir da atividade de estágio.

Depois de apresentado o referencial teórico, os procedimentos metodológicos são apresentados na sessão seguinte.

\section{PROCEDIMENTOS METODOLÓGICOS}

Este estudo se classifica como uma pesquisa exploratória e descritiva com base em procedimentos técnicos de cunho bibliográfico, documental e empírico, fazendo uso dos métodos quantitativo e qualitativo para poder melhor entender o fenômeno.

O primeiro passo realizado foi uma pesquisa acerca de estudos anteriores, buscando aqueles que descem subsídios a esta pesquisa. Assim, foi utilizado como referência o questionário construído por Michels (2012), com questões fechadas, contudo foram feitas algumas adaptações no questionário, incluindo questões de outros autores (MELLO e CASTRO et al., 2007; SANTOS; SCHMIDT, 2008; RAIA; MELZ, 2011), além de algumas questões novas. O questionário também disponibilizava um espaço onde os respondentes poderiam expressar suas opiniões ou deixar algum comentário. Este trabalho foi iniciado com 30 questões assertivas.

Também foi realizada uma entrevista com o coordenador da disciplina de estágio, utilizando-se de um roteiro semiestruturado composto por seis perguntas abertas a respeito do estágio curricular supervisionado obrigatório. Dessa forma, o conteúdo da entrevista foi utilizado como parâmetro para verificação a adequação das questões na composição do questionário.

O público de interesse desta pesquisa foram alunos e ex-alunos do curso de Administração da UFMT - Câmpus Rondonópolis, totalizando, inicialmente, 729 potenciais respondentes no ano de 2016. Contudo, tendo a preocupação no primeiro momento em extrair o público alvo, ou seja, somente os alunos que fizeram ou que estivessem fazem o estágio obrigatório. O questionário contemplava aspectos demográficos a respeito dos participantes e, subsequentemente, as questões foram divididas em cinco blocos. Com base em uma escala Likert de 11 pontos, os respondentes deveriam sinalizar as contribuições do estágio de acordo com as suas percepções, indicando notas de 0 (Zero) a 10 (Dez). 
Depois de finalizado, o questionário foi incluído no software Qualtrics para a realização de um préteste. Após o feedback proporcionado por alguns alunos que responderam inicialmente as perguntas, foram realizados alguns ajustes e criada a versão final do questionário pronto para ser lançado.

Os questionários foram enviados por e-mail a 729 alunos, sendo que $9 \%$ apresentou falha de endereço. A pesquisa foi encerrada um mês depois de seu início com 101 respostas válidas, apresentando uma taxa de retorno de $15,20 \%$.

Os dados quantitativos foram tabulados e analisados, com auxílio do software SPSS 20 (Statistical Package of Social Sciences), fazendo uso das seguintes técnicas estatísticas: análise fatorial, confiabilidade, normalidade e homogeneidade, análise de correlação e comparativo entre médias.

\section{ANÁLISE DOS RESULTADOS QUANTITATIVOS}

A primeira análise dos dados realizada foi a análise de fatores, utilizando o Teste de esfericidade de Bartlett e KMO (Medida de adequação da Amostra), e utilizando da opção de método de Varimax. As 30 (trintas) questões adaptadas de Michels (2012) anteriormente incorporadas em blocos, foram redistribuídas para 6 (seis) fatores, tendo os valores do teste de $\mathrm{KMO}$ em 0,850 e a variância total explicada em 76,30\%.

Porém, tendo em vista que 5 (cinco) questões agruparam de maneira diferente, foi feito uma nova análise fatorial aplicando apenas as 25 (vinte e cinco) questões, utilizando-se do mesmo teste e método.

A partir desta nova análise, o KMO teve uma pequena redução para 0,840, conforme o Quadro 1. Porém, continua apresentando um resultado aceitável de que matriz de dados está boa para realização da demais análises, pois está próximo de 1 , levando em consideração que o Índice de Significância (SIG) também se apresentou favorável, sendo SIG < 0,050, ou seja, há significância nos dados.

\section{QUADRO 1 - Teste de Bartlett e KMO}

\begin{tabular}{|l|l|r|}
\hline \multicolumn{2}{|l|}{ Medida Kaiser-Meyer-Olkin Medida de adequação da Amostra } & 0,840 \\
\hline \multirow{2}{*}{ Teste de esfericidade de Bartlett } & Chi-quadrado aprox. & $2.244,848$ \\
\cline { 2 - 3 } & Df & 300 \\
\cline { 2 - 3 } & Sig. & 0,000 \\
\hline
\end{tabular}

Fonte: Dados da pesquisa.

A Tabela 1 mostra a variância total explicada dos componentes desta nova análise fatorial realizada em que se pode notar que houve uma diminuição nos fatores. Porém, estes 5 (cinco) fatores, conseguem explicar aproximadamente $78 \%$ da variância total dos dados, o que pode ser considerado uma boa explicação.

TABELA 1 - Variação total explicada

\begin{tabular}{cccccccccc}
\hline & \multicolumn{4}{c}{ Fatores } & \multicolumn{4}{c}{ Valores próprios iniciais } & \multicolumn{3}{c}{$\begin{array}{c}\text { Somas de extração de } \\
\text { carregamentos ao quadrado }\end{array}$} \\
\cline { 2 - 12 } & Total & $\begin{array}{c}\text { \% de } \\
\text { variação }\end{array}$ & \% cumulativa & Total & $\begin{array}{c}\text { \% de } \\
\text { variação }\end{array}$ & \% cumulativa & Total & $\begin{array}{c}\text { \% de } \\
\text { variação }\end{array}$ & \% cumulativa \\
\hline 1 & 12,853 & 51,411 & 51,411 & 12,853 & 51,411 & 51,411 & 4,884 & 19,538 & 19,538 \\
2 & 2,564 & 10,257 & 61,668 & 2,564 & 10,257 & 61,668 & 4,622 & 18,489 & 38,026 \\
3 & 1,612 & 6,447 & 68,115 & 1,612 & 6,447 & 68,115 & 4,498 & 17,994 & 56,020 \\
4 & 1,377 & 5,506 & 73,621 & 1,377 & 5,506 & 73,621 & 3,042 & 12,170 & 68,190 \\
5 & 1,064 & 4,256 & 77,877 & 1,064 & 4,256 & 77,877 & 2,422 & 9,688 & 77,877 \\
\hline
\end{tabular}

Fonte: Dados da pesquisa. 
A Tabela 2 mostra a matriz dos componentes após a rotação, tendo a distribuição da carga dos fatores, deixando claro a existência dos 5 (cinco) fatores e somente as altas cargas das variáveis para um melhor entendimento. A partir desta análise, foi possível identificar que as questões adaptadas do questionário de Michels (2012), se encaixam nos fatores, sendo o fator 1, oportunidade de aprendizagem; fator 2, interdisciplinaridade; fator 3 , metodologia; fator 4 , suporte e por último o fator 5 , objetivos de estágio.

\section{TABELA 2 - Matriz de componente rotativo}

\begin{tabular}{lc}
\hline Questões & $\mathbf{1}$ \\
\hline Permite a aplicação prática dos conhecimentos teóricos aprendidos durante o curso. & 0,820 \\
O estágio agrega novos valores para a futura profissão. & 0,783 \\
$\begin{array}{l}\text { O estágio proporciona oportunidades para ajudar a definir sua carreira (ajuda a confirmar ou } \\
\text { repensar na escolha profissional). }\end{array}$ & 0,771 \\
O estágio proporciona conhecimento prático para formação profissional. & 0,768 \\
Permite aprofundar sua área de interesse. & 0,742 \\
O estágio supervisionado contribui para formação acadêmica. & 0,734
\end{tabular}

O projeto de estágio alinha o tema, ao problema de pesquisa e aos objetivos do TC.

A normativa (regulamento) do estágio supervisionado do curso auxilia no desenvolvimento das atividades propostas.

A divisão do estágio em I, II, III e IV facilita o entendimento.

A metodologia empregada nas etapas do estágio proporciona melhor aquisição de conhecimento.

O curso oferece acompanhamento e orientações necessárias para a realização das atividades desenvolvidas durante o estágio.

Fonte: Dados da pesquisa.

Após fazer a análise de fatores, o segundo passo foi checar a confiabilidade da escala, utilizando do modelo de Alfa Cronbach, que é a medida mais comum de confiabilidade. Os resultados confirmam que a confiabilidade, considerando que valores estão acima de 0,700, sendo aceitável como mostra a Tabela 3. 
Tabela 3 - Confiabilidade da escala

\begin{tabular}{llc}
\hline \multicolumn{1}{c}{ Fatores } & \multicolumn{1}{c}{ Questões } & $\begin{array}{c}\text { Alfa } \\
\text { Cronbach }\end{array}$ \\
\hline & Permite a aplicação prática dos conhecimentos teóricos aprendidos durante o curso. \\
& Permite aprofundar sua área de interesse. \\
& O estágio supervisionado contribui para formação acadêmica. \\
$\begin{array}{l}\text { Oportunidade de } \\
\text { aprendizagem }\end{array}$ & O estágio proporciona conhecimento prático para formação profissional. \\
& $\begin{array}{l}\text { O estágio agrega novos valores para a futura profissão. } \\
\text { O estágio proporciona oportunidades para ajudar a definir sua carreira (ajuda a confirmar } \\
\text { ou repensar na escolha profissional). }\end{array}$
\end{tabular}

O projeto de estágio permite uma visão prévia do TC.

Realizar o estágio facilita o levantamento dos dados necessários para elaboração do TC.

Interdisciplinaridade Há relação direta entre o estágio e o tema do TC.

O projeto de estágio alinha o tema, ao problema de pesquisa e aos objetivos do TC.

As atividades do estágio contribuem para a elaboração do TC.

Realizar um diagnóstico empresarial para a melhoria dos processos organizacionais.

Observar e avaliar as práticas gerenciais realizadas na empresa.

A normativa (regulamento) do estágio supervisionado do curso auxilia no desenvolvimento

Metodologia das atividades propostas.

A divisão do estágio em I, II, III e IV facilita o entendimento.

A metodologia empregada nas etapas do estágio proporciona melhor aquisição de conhecimento.

Ajudar a empresa atingir os seus objetivos de crescimento e desenvolvimento.

O orientador está presente nos horários propostos.

Suporte

Recebimento de orientação com relação aos documentos.

O curso oferece acompanhamento e orientações necessárias para a realização das atividades desenvolvidas durante o estágio.

O orientador participa ou dá suporte no local de desenvolvimento do estágio.

Atender preferencialmente aos interesses do aluno em formação.

Objetivo de estágio

Proporcionar maior segurança ao estagiário, por meio da vivência prática da administração.

Estudar um tema específico em um setor da empresa.

Comparar a prática com a teoria.

Fonte: Dados da pesquisa.

A partir dessa redistribuição de fatores foram realizados os testes de normalidade e da homogeneidade para a identificação de qual tipo de teste (paramétricos ou não paramétricos) deve ser usado para proceder na análise de correlação e o comparativo entre as médias.

Desse modo, utilizando-se do Teste de Kolmogorov-smirnov para verificação da normalidade, os resultados indicaram não haver normalidade na distribuição dos dados levando em consideração que alguns fatores apresentaram o SIG < 0,050, portanto a amostra possui uma distribuição não normal, rejeitando a hipótese nula, ou seja, o efeito previsto não existe. 
Também foi realizado o Teste de Levene, que tem como intuito comparar mais de duas variâncias, verificando assim se há ou não homogeneidade entre elas. Os resultados indicam haver homogeneidade da variância entre os dados considerando que o SIG $>0,050$, assim as variâncias não são significativamente diferentes. Os dados estão apresentados na Tabela 4.

TABELA 4 - Teste de normalidade e homogeneidade da variância

\begin{tabular}{|c|c|c|c|c|c|c|c|c|}
\hline \multicolumn{5}{|c|}{ Teste de normalidade } & \multicolumn{4}{|c|}{ Teste de homogeneidade da variância } \\
\hline \multirow{2}{*}{ Fatores } & \multirow{2}{*}{ Gênero } & \multicolumn{3}{|c|}{ Kolmogorov-Smirnov } & \multirow{2}{*}{$\begin{array}{l}\text { Levene } \\
\text { Statistic }\end{array}$} & \multirow{2}{*}{ df1 } & \multirow{2}{*}{ df2 } & \multirow{2}{*}{ Sig } \\
\hline & & Estatíst. & Df & Sig & & & & \\
\hline \multirow{2}{*}{$\begin{array}{l}\text { Oportunidade de } \\
\text { aprendizagem }\end{array}$} & Feminino & 0,120 & 53 & 0,053 & \multirow[b]{2}{*}{0,652} & \multirow[b]{2}{*}{1} & \multirow[b]{2}{*}{85} & \multirow[b]{2}{*}{0,422} \\
\hline & Masculino & 0,154 & 34 & 0,034 & & & & \\
\hline \multirow{2}{*}{ Interdisciplinaridade } & Feminino & 0,085 & 53 & 0,200 & \multirow{2}{*}{0,068} & \multirow{2}{*}{1} & \multirow{2}{*}{85} & \multirow[b]{2}{*}{0,794} \\
\hline & Masculino & 0,199 & 34 & 0,001 & & & & \\
\hline \multirow[b]{2}{*}{ Metodologia } & Feminino & 0,054 & 53 & 0,200 & \multirow[b]{2}{*}{1,224} & \multirow[b]{2}{*}{1} & \multirow[b]{2}{*}{85} & \multirow[b]{2}{*}{0,272} \\
\hline & Masculino & 0,162 & 34 & 0,024 & & & & \\
\hline \multirow[b]{2}{*}{ Suporte } & Feminino & 0,082 & 53 & 0,200 & \multirow[b]{2}{*}{0,990} & \multirow[b]{2}{*}{1} & \multirow[b]{2}{*}{85} & \multirow[b]{2}{*}{0,323} \\
\hline & Masculino & 0,100 & 34 & 0,200 & & & & \\
\hline \multirow[b]{2}{*}{ Objetivos de estágio } & Feminino & 0,097 & 53 & 0,200 & \multirow[b]{2}{*}{0,124} & \multirow[b]{2}{*}{1} & \multirow[b]{2}{*}{85} & \multirow[b]{2}{*}{0,725} \\
\hline & Masculino & 0,152 & 34 & 0,046 & & & & \\
\hline
\end{tabular}

Fonte: Dados da pesquisa.

Foi feita a correlação bivariada como mostra a Tabela 5, isto é, a correlação entre duas variáveis, neste caso as demográficas e os fatores. Foi utilizando o coeficiente de correlação de Spearman, considerado como um teste não-paramétrico, tendo aplicabilidade neste caso devido a constatação de dados não-normais, conforme o resultado da Tabela 4.

TABELA 5 - Correlação bivariada (Spearman)

\begin{tabular}{|c|c|c|c|c|c|c|c|c|c|c|}
\hline Correlação & & $\begin{array}{c}\text { Situação } \\
\text { de } \\
\text { estágio }\end{array}$ & $\begin{array}{c}\text { Etapas } \\
\text { do } \\
\text { estágio }\end{array}$ & $\begin{array}{l}\text { Situação } \\
\text { na UFMT }\end{array}$ & Semestre & $\begin{array}{c}\text { Períodos } \\
\text { do } \\
\text { estudo } \\
\end{array}$ & Gênero & Idade & $\begin{array}{l}\text { Estudo e } \\
\text { trabalho }\end{array}$ & $\begin{array}{c}\text { Local de } \\
\text { estágio }\end{array}$ \\
\hline $\begin{array}{l}\text { Oportunidade de } \\
\text { aprendizagem }\end{array}$ & $\begin{array}{l}\text { C.c } \\
\text { Sig }\end{array}$ & $\begin{array}{l}0,080 \\
0,463\end{array}$ & $\begin{array}{r}-0,022 \\
0,867\end{array}$ & $\begin{array}{l}0,126 \\
0,246\end{array}$ & $\begin{array}{r}-0,031 \\
0,796\end{array}$ & $\begin{array}{l}0,059 \\
0,588\end{array}$ & $\begin{array}{l}0,021 \\
0,850\end{array}$ & $\begin{array}{r}-0,007 \\
0,946\end{array}$ & $\begin{array}{l}0,104 \\
0,337\end{array}$ & $\begin{array}{r}-, 070 \\
, 518\end{array}$ \\
\hline Interdisciplinaridade & $\begin{array}{l}\text { C.c } \\
\text { Sig }\end{array}$ & $\begin{array}{r}-0,111 \\
0,306\end{array}$ & $\begin{array}{r}-0,153 \\
0,238\end{array}$ & $\begin{array}{r}-0,209 \\
0,052\end{array}$ & $\begin{array}{r}-0,041 \\
0,730\end{array}$ & $\begin{array}{l}0,034 \\
0,751\end{array}$ & $\begin{array}{r}-0,025 \\
0,816\end{array}$ & $\begin{array}{l}0,074 \\
0,496\end{array}$ & $\begin{array}{r}-0,019 \\
0,858\end{array}$ & $\begin{array}{r}-, 319 \\
, 003\end{array}$ \\
\hline Metodologia & $\begin{array}{l}\text { C.c } \\
\text { Sig }\end{array}$ & $\begin{array}{r}-0,095 \\
0,383\end{array}$ & $\begin{array}{l}0,063 \\
0,631\end{array}$ & $\begin{array}{r}-0,068 \\
0,531\end{array}$ & $\begin{array}{r}-0,101 \\
0,392\end{array}$ & $\begin{array}{l}0,024 \\
0,826\end{array}$ & $\begin{array}{r}-0,163 \\
0,131\end{array}$ & $\begin{array}{l}0,053 \\
0,625\end{array}$ & $\begin{array}{l}0,076 \\
0,484\end{array}$ & $\begin{array}{r}-, 176 \\
, 102\end{array}$ \\
\hline Suporte & $\begin{array}{l}\text { C.C } \\
\text { Sig }\end{array}$ & $\begin{array}{l}0,133 \\
0,299\end{array}$ & $\begin{array}{l}0,063 \\
0,630\end{array}$ & $\begin{array}{l}0,092 \\
0,394\end{array}$ & $\begin{array}{l}0,054 \\
0,648\end{array}$ & $\begin{array}{l}0,111 \\
0,307\end{array}$ & $\begin{array}{l}0,091 \\
0,402\end{array}$ & $\begin{array}{r}-0,007 \\
0,952\end{array}$ & $\begin{array}{l}0,124 \\
0,253\end{array}$ & $\begin{array}{r}-, 106 \\
, 330\end{array}$ \\
\hline Objetivos de estágio & $\begin{array}{l}\text { C.C } \\
\text { Sig }\end{array}$ & $\begin{array}{r}-0,037 \\
0,736\end{array}$ & $\begin{array}{l}0,034 \\
0,797\end{array}$ & $\begin{array}{r}-0,101 \\
0,350\end{array}$ & $\begin{array}{r}-0,072 \\
0,539\end{array}$ & $\begin{array}{r}-0,131 \\
0,226\end{array}$ & $\begin{array}{r}-0,135 \\
0,212\end{array}$ & $\begin{array}{l}0,028 \\
0,795\end{array}$ & $\begin{array}{r}-0,001 \\
0,993\end{array}$ & $\begin{array}{l}006 \\
, 958\end{array}$ \\
\hline
\end{tabular}

Fonte: Dados da pesquisa.

Com relação ao resultado, pode-se notar que apenas há valor de significância entre o fator de interdisciplinaridade e a variável local de estágio, sendo o $S I G<0,050$, mesmo o coeficiente de correlação (c.c) dando negativo; portanto, pode ser concluído que os meios utilizados para conseguir o local de estágio (funcionário da empresa, por indicações, por agências, pela universidade, etc.) estão correlacionado com fator interdisciplinaridade, levando em consideração que neste fator abrange o alinhamento do estágio com o Trabalho de Curso (TC), ou seja, um aluno que é funcionário da empresa, ou conseguiu o local por indicação pode ter maior abertura de espaço para realizar o seu TC. 
Esse entendimento verifica-se nos comentários deixado pelos respondentes como no comentário 2: "[...] muitos que consegue é porque trabalha na empresa, indicação é empresa da família [...]". No comentário 8: "[...] no meu caso como eu trabalhava o estágio foi tranquilo [...]". E também no comentário 19: "[...] meu caso mesmo, só consegui porque, já trabalhava na empresa". Quanto às demais variáveis, o SIG apresentouse maior que 0,050 , logo não teve valor significativo.

A seguir, são apresentados os resultados do comparativo entre médias, empregando testes nãoparamétricos, de Mann-Whitney e o de Kruskal-Wallis. Todos os testes apresentados têm por base as hipóteses da pesquisa.

\section{$H_{1}$ : há diferença entre as percepções dos alunos e ex-alunos de acordo com os gêneros:}

Pode-se observar na Tabela 6 que não há nenhum nível de significância (SIG > 0,050) entre a variável gênero e os fatores considerados no estágio, portando as percepções dos alunos não variam de acordo com os gêneros. Assim, pode-se dizer que não há diferenças estatisticamente significativas (a um nível de significância de 0,050 ) entre as percepções dos alunos e a variável gênero. Desta forma, a hipótese $\mathrm{H}_{1}$ não é corroborada.

Tabela 6 - Comparações entre os gêneros - Teste de Mann-Whitney

\begin{tabular}{lrrrrr}
\hline \multicolumn{1}{c}{ Testes } & $\begin{array}{c}\text { Oportunidade de } \\
\text { aprendizagem }\end{array}$ & Interdisciplinaridade & Metodologia & $\begin{array}{c}\text { Suporte } \\
\text { Objetivos de } \\
\text { estágio }\end{array}$ \\
\hline Mann-Whitney U & 879,000 & 874,000 & 727,000 & 804,000 & 757,000 \\
Wilcoxon W & $2.310,000$ & $1.469,000$ & $1.322,000$ & $2.235,000$ & $1.352,000$ \\
Z & $-0,191$ & $-0,235$ & $-1,514$ & $-0,844$ & $-1,253$ \\
Sig. Assint. (2 caudas) & 0,848 & 0,814 & 0,130 & 0,399 & 0,210 \\
\hline
\end{tabular}

Fonte: Dados da pesquisa.

$\mathrm{H}_{2}$ : há diferença entre as percepções dos alunos e os semestres que estão cursando

A análise apresentada na Tabela 7 não identificou diferenças estatisticamente significativas entre as percepções dos alunos e os semestres em que estão cursando.

TABELA 7 - Comparações entre os semestres - Teste de Kruskal-Wallis

\begin{tabular}{lrrrrr}
\hline \multicolumn{1}{c}{ Testes } & $\begin{array}{c}\text { Oportunidade de } \\
\text { aprendizagem }\end{array}$ & Interdisciplinaridade & Metodologia & $\begin{array}{c}\text { Suporte } \\
\text { Objetivos de } \\
\text { estágio }\end{array}$ \\
\hline Chi-quadrado & 5,156 & 0,568 & 1,995 & 5,059 & 1,168 \\
Df & 3 & 3 & 3 & 3 & 3 \\
$\begin{array}{l}\text { Significância } \\
\text { Assintótica }\end{array}$ & 0,161 & 0,904 & 0,573 & 0,168 & 0,761 \\
\hline Fonte: Dados da pesquisa & & & & &
\end{tabular}

Fonte: Dados da pesquisa. 
$H_{3}$ : há diferença entre as percepções dos alunos e as etapas do estágio:

A variável etapas do estágio mostrou haver diferenças estatisticamente significativas com relação às percepções dos alunos, conforme a Tabela 8 apresenta. Assim, há diferença na percepção das etapas do estágio com relação ao suporte dado. A hipótese $3\left(\mathrm{H}_{3}\right)$ foi confirmada, indicando que há diferenças estatisticamente significativas entre as percepções e as etapas do estágio.

TABELA 8 - Comparações entre etapas do estágio - Teste de Kruskal-Wallis

\begin{tabular}{lrrrrr}
\hline \multicolumn{1}{c}{ Testes } & $\begin{array}{c}\text { Oportunidade de } \\
\text { aprendizagem }\end{array}$ & Interdisciplinaridade & Metodologia & $\begin{array}{c}\text { Suporte } \\
\text { Objetivos de } \\
\text { estágio }\end{array}$ \\
\hline Chi-quadrado & 7,488 & 5,842 & 4,601 & 12,755 & 4,578 \\
Df & 6 & 6 & 6 & 6 & 6 \\
$\begin{array}{l}\text { Significância } \\
\text { Assintótica }\end{array}$ & 0,278 & 0,441 & 0,596 & 0,047 & 0,599 \\
\hline
\end{tabular}

Fonte: Dados da pesquisa.

$\mathrm{H}_{4}$ : há diferença entre as percepções dos alunos e ex-alunos e os períodos do estudo:

A Tabela 9 mostra não haver diferenças estatisticamente significativas com relação às percepções dos alunos e a variável períodos do estudo, logo as percepções não variam de acordo com os períodos do estudo que os alunos estudam ou estudaram, o que leva a não corroboração da hipótese $\mathrm{H}_{4}$.

TABELA 9 - Comparações entre períodos do estudo - Teste de Kruskal-Wallis

\begin{tabular}{lrrrrr}
\multicolumn{1}{c}{ Testes } & $\begin{array}{c}\text { Oportunidade de } \\
\text { aprendizagem }\end{array}$ & Interdisciplinaridade & Metodologia & $\begin{array}{c}\text { Suporte } \\
\text { Objetivos de } \\
\text { estágio }\end{array}$ \\
\hline Chi-quadrado & 0,995 & 0,102 & 0,634 & 2,793 & 2,023 \\
Df & 2 & 2 & 2 & 2 & 2 \\
$\begin{array}{l}\text { Significância } \\
\text { Assintótica }\end{array}$ & 0,608 & 0,950 & 0,728 & 0,247 & 0,364 \\
\hline
\end{tabular}

Fonte: Dados da pesquisa.

$\mathrm{H}_{5}$ : há diferença entre as percepções dos alunos e ex-alunos sobre o estágio:

A análise a seguir apresentada na Tabela 10, não identificou nenhuma diferença estatisticamente significativa, assim fica constatado que não há diferença entre as percepções dos alunos e ex-alunos sobre o estágio. Com isso a hipótese $\mathrm{H}_{5}$ não é corroborada.

TABELA 10 - Comparações entre situação do aluno - Teste de Kruskal-Wallis

\begin{tabular}{lrrrrr}
\hline \multicolumn{1}{c}{ Testes } & $\begin{array}{c}\text { Oportunidade de } \\
\text { aprendizagem }\end{array}$ & Interdisciplinaridade & Metodologia & $\begin{array}{c}\text { Suporte } \\
\text { Objetivos de } \\
\text { estágio }\end{array}$ \\
\hline Chi-quadrado & 1,361 & 3,766 & 0,398 & 0,735 & 0,885 \\
Df & 1 & 1 & 1 & 1 & 1 \\
$\begin{array}{l}\text { Significância } \\
\text { Assintótica }\end{array}$ & 0,243 & 0,052 & 0,528 & 0,391 & 0,347 \\
\hline
\end{tabular}

Fonte: Dados da pesquisa. 


\section{ANÁLISE DOS DADOS QUALITATIVOS}

Após trabalhar os dados obtidos no espaço aberto destinado aos respondentes para expressarem suas opiniões ou deixar algum comentário, passa-se neste momento ao processo de interpretação e busca de significados por meio da análise de categorias (parceria, obrigatoriedade, adequação, oportunidade e suporte), assim as interpretações foram integradas aos conceitos e conhecimentos prévios. Os comentários passaram a ser tratados pela letra $\mathrm{C}$ seguida de um número que indica o respondente, por exemplo, $\mathrm{C} 1$, para o comentário do respondente 1 .

\section{Parceria}

$\mathrm{Na}$ categoria parceria, compreende-se nesta pesquisa como convênio formal da universidade com empresas, formação de cadastro e incentivos. Esta categoria é sustentada por autores (MICHELS, 2012; MURARI; HELAL, 2009; FESTINALLI; CANOPF; BERTUOL, 2007; ALMEIDA; LAGEMANN; SOUSA, 2006; MAÇANEIRO, 2004; MINTZBERG; GOSLING, 2003) que apontam que o ensino e o campo de atuação devem estar interligados e interagindo de forma satisfatória. Essa interação é importante para o processo de aprendizagem teórico-prático, principalmente no caso da formação do acadêmico em administração, visto que a educação gerencial requer a experiência prática para aprofundamento de conhecimentos, habilidades e atitudes proporcionando assim a percepção do estagiário na sua futura realidade profissional. Desta forma, deve ser respaldada a parceria entre universidade e organizações.

No cruzamento de informações levantadas foram analisadas qualitativamente as percepções, e no que diz respeito à parceria, os respondentes mencionam a falta desta parceria entre a universidade e os empresários locais dificultando associação da teoria com a prática. Há indicação também da falta de cultura, ou seja, a falta de compreensão da importância do estágio curricular obrigatório para o aluno e para empresa, e assim atrasando as atividades do estágio refletindo em consequências futuras como reprovação da matéria e até mesmo a não colação de grau.

Essa análise faz um elo com o resultado da pesquisa quantitativa no que se refere a correlação do local do estágio sobre a influência interdisciplinaridade (Tabela 5), anteriormente explicada. O Quadro 2 mostra os comentários feitos pelos respondentes quanto às questões envolvendo a categoria parceria. 
QUADRO 2 - Comentários dos respondentes - Parceria

\begin{tabular}{|c|c|}
\hline Respondente & Comentário \\
\hline $\mathrm{C} 2$ & $\begin{array}{l}\text { "[...] os empresários não possuem em sua cultura ter dentro da empresa um estagiário não remunerado, e } \\
\text { independente da forma que se apresente, por mais formal que seja, eles ainda têm receio [...]". }\end{array}$ \\
\hline C5 & $\begin{array}{l}\text { "Sobre o aluno fazer o estágio na empresa na área na qual queira atuar, não é tão fácil pois as empresas não } \\
\text { liberam todas as informações, e universidade não oferece ao aluno empresas disponíveis para estagiar". }\end{array}$ \\
\hline $\mathrm{C} 7$ & $\begin{array}{l}\text { "[...] a UFMT não possuía parcerias com empresas, ou seja, o aluno (a) possuía um prazo estabelecido para } \\
\text { encontrar uma empresa que o aceitasse a fazer o estágio supervisionado [...]". }\end{array}$ \\
\hline $\mathrm{C} 8$ & $\begin{array}{l}\text { "[...] falta para as coordenações de estágio e do curso de Administração, realizarem parcerias com empresas e } \\
\text { órgãos públicos/privados [...]". }\end{array}$ \\
\hline C12 & $\begin{array}{l}\text { "[...] se a Universidade tivesse um leque de empresas cadastradas para cada tipo de curso, onde pudessem } \\
\text { mandá-los para a prática do Estágio de acordo com o curso e a área. Com isso, facilitaria o aprendizado do aluno, } \\
\text { e com participação das organizações públicas e privadas, a Universidade poderiam ser um elo ou uma ponte } \\
\text { entre os alunos e os empresários aquecendo o mercado de trabalho e possibilitando o ganho da experiência de } \\
\text { campo e experiência teoria mais facilmente. [...]". }\end{array}$ \\
\hline C15 & $\begin{array}{l}\text { "A faculdade deve estar sempre em busca de empresas para auxiliar a teoria com a prática. Infelizmente a nossa, } \\
\text { está bem distante dessa situação". }\end{array}$ \\
\hline C18 & $\begin{array}{l}\text { "[...] deveria pelo menos dar suporte aos mesmos indicando empresas, que possam receber seus respectivos } \\
\text { alunos para desenvolver tal atividade [...]". }\end{array}$ \\
\hline
\end{tabular}

Fonte: Dados da pesquisa.

\section{Obrigatoriedade}

A categoria obrigatoriedade é entendida como a dificuldade de o aluno realizar o estágio obedecendo às regras. Tratar sobre a obrigatoriedade no estágio no curso de administração remete-se aos extremos em convergência e divergência. Para alguns autores (ALMEIDA; LAGEMANN; SOUSA, 2006) a obrigatoriedade na grade curricular do curso de administração é um fator que remete a uma análise profunda, pois o estágio está sendo descaracterizado, perdendo o objetivo central e a sua forma, tornando-se apenas uma formalidade.

$\mathrm{Na}$ análise da categoria obrigatoriedade, os respondentes fazem apontamentos pelo estágio ser obrigatório, ser revestido de regras, como o cumprimento de carga horária, e mencionam que durante esse período o aluno não tem suporte. É possível inferir que os alunos estão vendo na obrigatoriedade um obstáculo para a conclusão de curso, e esse entendimento não deveria persistir no universo pesquisado, especialmente por conta da importância do estágio em possibilitar ao aluno crescer e se desenvolver profissionalmente. Outros autores (FESTINALLI; CANOPF; BERTUOL, 2007; ROESCH, 1999) relatam que a obrigatoriedade é uma condição necessária para a aprendizagem e aprofundamento dos conhecimentos e habilidades, sendo o estágio um elemento articulador para a formação do acadêmico em administração. No entanto, pode-se indicar que há um contraponto à questão da rigidez das regras, conforme a percepção indicada no comentário C14 descrevendo que "Comecei o estágio em uma empresa e depois troquei. Gostei da metodologia empregada, pois não é necessário que você fique horas fixas na empresa, a proposta de analisar um possível problema dentro de uma empresa e apresentar uma solução contribui muito para a formação do aluno [...]". Porém, devem-se levar em conta as fragilidades, algumas apontadas no Quadro 3. 
QUADRO 3 - Comentários dos respondentes - Obrigatoriedade

\begin{tabular}{|c|c|}
\hline Respondente & Comentário \\
\hline C4 & $\begin{array}{l}\text { "As horas de estágios são longas e ficamos sem saber o que fazer em caso de não implementação do projeto de } \\
\text { estágio III, visto que é um direito da empresa não implementar nossas sugestões". }\end{array}$ \\
\hline C9 & "Diminuir a carga horaria do estágio". \\
\hline C10 & "Creio que não deveria ser obrigatório". \\
\hline C13 & $\begin{array}{l}\text { "Apenas acho desnecessário o estágio I, II, III e IV. / Poderia fazer uma compactação dos mesmos e excluir o } \\
\text { estágio IV pois no final acaba criando barreiras para formação de alguns alunos que deixaram para última hora". }\end{array}$ \\
\hline C18 & "A universidade por colocar o estágio como algo OBRIGATÓRIO para o aluno [...]". \\
\hline C19 & $\begin{array}{l}\text { "A universidade não deveria exigir o estágio como algo OBRIGATÓRIO, porque, nem sempre se consegue } \\
\text { empresas dispostas a ensinar o estagiário ou que queiram abrir suas portas para recebe-los. [...]". }\end{array}$ \\
\hline
\end{tabular}

Fonte: Dados da pesquisa.

\section{Adequação}

Quanto à categoria adequação, pode-se entender como o conciliar o estágio obrigatório com as atividades de ensino e à elaboração do TC. Sobre isto, alguns autores (AQUINO; TOMASSINI, 2008; ALMEIDA; LAGEMANN; SOUSA, 2006) relatam que o estágio supervisionado é algo antigo, porém ainda há discussão entorno do que se refere a sua validade e operacionalização nas estruturas curriculares, especialmente com respeito à forma que tem sido aplicado. Sob a ótica de alguns respondentes o estágio não cooperou com esse alinhamento com o TC e por fim dificultou o desenvolvimento das atividades, conforme revela o Quadro 4.

QUADRO 4 - Comentários dos respondentes - Adequação
\begin{tabular}{|c|l|}
\hline Respondente & \multicolumn{1}{c|}{ Comentário } \\
\hline C3 & $\begin{array}{l}\text { "A atividade de estágio deveria ser entendida pelos alunos como instrumento de facilitação para a realização do } \\
\text { TC. Quando se consegue combinar esses dois momentos, os alunos têm melhores condições para a conclusão } \\
\text { do curso, sem a necessidade de, muitas vezes, postergar a conclusão do curso por mais um ou dois semestres". }\end{array}$ \\
\hline C7 & $\begin{array}{l}\text { "[..] para não reprovar da disciplina de estágio supervisionado, realizavam os estágios na área que a organização } \\
\text { permitisse, muitas vezes essa área proposta pela empresa, não era a que o aluno (a) gostaria de desenvolver seu } \\
\text { TC". }\end{array}$ \\
\hline C17 & $\begin{array}{l}\text { "As metodologias aplicadas para os estagiários não estão alinhadas com as necessidades de conhecimentos para } \\
\text { realização do TC e das atividades de estágio, pois os conteúdos necessários e as ferramentas necessárias são } \\
\text { aplicadas durante ou depois das fases de cada estágio dificultando um bom desenvolvimento das atividades, } \\
\text { ocorrendo retrabalhos e pouco aproveitamento e desenvolvimento dessa oportunidade prática". }\end{array}$ \\
\hline
\end{tabular}

Fonte: Dados da pesquisa.

\section{Oportunidade}

Na categoria oportunidade, entende-se como o acesso do aluno à organização em que fará o estágio e o alinhamento da teoria com a prática. Esta compreensão esta alicerçada pelos fundamentos teóricos de autores (COLOMBO; BALLÃO, 2014; MICHELS, 2012; IEL, 2010; FESTINALLI; CANOPF; BERTUOL, 2007; FREY; FREY, 2002; ROESCH, 1999) que indicam que o estágio oferece ao estudante a oportunidade de colocar em prática o conhecimento adquirido na sala de aula, proporcionando ao aluno um momento para sistematização e confrontação desta teoria com a prática. Desta forma, destaca-se a função social da parte concedente do estágio nessa integração do aluno, assegurando o acesso à organização sob a supervisão de 
um profissional para orientar e corrigir, quando necessário, durante o desenvolvimento das atividades, com a intenção de que o aluno-estagiário venha desenvolver um excelente projeto de estágio.

\section{Suporte}

A categoria suporte pode ser entendida como a participação efetiva do orientador no desenvolvimento do estágio na universidade e na empresa. Este entendimento está amparado nas considerações feitas por autores (FESTINALLI; CANOPF; BERTUOL, 2007; FREY; FREY, 2002; ROESCH, 1999) que estabelecem que o estágio supervisionado é uma experiência importante para formação profissional do administrador, mas sugere-se uma análise quanto a sua implementação na estrutura universitária e na operacionalização, levando em consideração aspectos como a integração entre universidade e organizações que abrange itens como parceria, cultura, obrigatoriedade, adequação e oportunidade, e o relacionamento da universidade para com o aluno, englobando pontos como disponibilidade de professores-orientadores e suporte em apoio a projetos.

No que se refere ao suporte, evidenciou-se pelas respostas dos pesquisados que a grande maioria reportou dificuldade de coordenar atividade de estágio com a disponibilidade de professores-orientadores, particularmente na presença junto à empresa concedente de estágio. Isso se torna um fator negativo, pois o aluno se sente despreparado para desenvolver um trabalho junto à empresa e isso tem mudado o foco do estágio a não colaborar com a elaboração do TC. Este aspecto foi apresentado, inclusive, nos resultados da análise quantitativa, onde considerou que há diferença na percepção com relação ao suporte dado e as etapas do estágio, conforme Tabela 8. O Quadro 5 evidencia as respostas sobre a categoria suporte.

QUADRO 5 - Comentários dos respondentes - Suporte

\begin{tabular}{|c|c|}
\hline Respondente & Comentário \\
\hline C1 & $\begin{array}{l}\text { "[...] espero que o Orientador que escolhi para o estágio } 2 \text { possa me ajudar de modo que não precise ficar } \\
\text { buscando ajuda com os alunos de outros semestres como fiz no estágio } 1[\ldots] \text { ". }\end{array}$ \\
\hline $\mathrm{C2}$ & $\begin{array}{l}\text { "A universidade não dá suporte em relação a indicação de alunos para estágio [...] Tem que se repensar certos } \\
\text { conceitos e fazer adaptação em relação ao suporte que é dado (ou melhor, não é dado) ao aluno para encontrar } \\
\text { uma empresa [...]". }\end{array}$ \\
\hline C7 & $\begin{array}{l}\text { "[...] o professor explicou a documentação necessária em sala de aula e não deu o suporte em caso de dúvidas } \\
{[\ldots] \text { ". }}\end{array}$ \\
\hline $\mathbf{C 8}$ & $\begin{array}{l}\text { "[...] na minha opinião não existe orientação, pois o professor apenas realiza uma ou duas aulas explicando o que } \\
\text { de fato é o estágio, seus benefícios e principalmente o que o aluno deve extrair do estágio. [...] falta } \\
\text { acompanhamento do professor orientador e do coordenador de estágio referente aos atingimentos de objetivos } \\
\text { que o aluno se pré-dispõem com a empresa [...]". }\end{array}$ \\
\hline C11 & "[...] nenhum professor foi a empresa para saber como tinha sido o estágio ou falado com o gerente [...]" \\
\hline C12 & "O estágio seria uma ferramenta mais aproveitada, se tivéssemos uma participação maior da Universidade [...]". \\
\hline C16 & $\begin{array}{l}\text { "O estágio seria muito bom para o desenvolvimento profissional, porém não proporciona adequadamente suporte } \\
\text { para elaboração. O orientador não tem paciência de explicar a prática devida para se fazer um trabalho adequado } \\
\text { aos alunos". }\end{array}$ \\
\hline
\end{tabular}

Fonte: Dados da pesquisa. 


\section{CONSIDERAÇÕES FINAIS}

O propósito deste trabalho foi analisar a contribuição do estágio supervisionado curricular obrigatório na formação do futuro administrador, a partir da percepção dos alunos e ex-alunos do curso de Administração, por meio da aplicação dos métodos quantitativos e qualitativos, tendo como principal ferramenta de coleta de dados um questionário composto por perguntas fechadas e abertas. Além do histórico da legislação sobre o assunto, a base teórica foi composta por estudos acerca do estágio supervisionado curricular obrigatório (LOURENÇO; LEMOS; JUNIOR, 2012; RAIA; MELZ, 2011; MURARI; HELAL, 2009; FESTINALLI; CANOPF; BERTUOL, 2007; MELLO e CASTRO et al., 2007; ALMEIDA; LAGEMANN; SOUSA, 2006; NASCIMENTO; TEODÓSIO, 2005).

Com base nas análises dos dados quantitativos, pode-se perceber que a redução dos fatores para 5 (cinco) se apresentou favorável, prosseguindo para as demais análises. A partir desta redistribuição de fatores foram realizados os testes de normalidade e da homogeneidade, apresentando dados não normalmente distribuídos (SIG < 0,050), porém com homogeneidade de suas variâncias (SIG > 0,050), a partir disso, adotou-se o uso dos testes não-paramétricos, envolvendo a análise de correlação e o comparativo entre as médias.

No resultado de análise de correlação houve apenas valor de significância entre o fator de interdisciplinaridade e a variável local de estágio, sendo o $\mathrm{SIG}<0,050$, justificado pela influência de como o aluno conseguiu o local de estágio. No fator da interdisciplinaridade que abrange o alinhamento do estágio com o TC, esta correlação também é evidenciada por meio da análise qualitativa.

Os resultados do comparativo entre as médias, baseando-se nas hipóteses lançadas nesta pesquisa, apresentaram que apenas a hipótese 3 foi corroborada, indicando que há diferença entre as percepções e as etapas do estágio com relação ao suporte dado aos alunos. Adicionalmente, esta hipótese também foi evidenciada pela análise qualitativa.

No tocante as análises dos dados qualitativos foram identificadas cinco categorias (parceria, obrigatoriedade, adequação, oportunidade e suporte) que permitiram salientar alguns aspectos para a contribuição do estágio para formação do futuro administrador. Os códigos mais evidenciados nos comentários foram relativos a problema ou fragilidades com o "suporte" e com a "parceria". Comparando com os estudos anteriores pode-se destacar alguns pontos. Os autores Raia e Melz (2011), Mello e Castro et al. (2007) e Nascimento e Teodósio (2005) se mostraram neutros nas suas conclusões, não corroborando para os resultados aqui obtidos. Já os estudos de Murari e Helal (2009), Festinalli, Canopf e Bertuol (2007), Almeida, Lagemann e Sousa (2006) encontraram resultados positivos relativos ao estágio o que contrapõem aos resultados obtidos por esta pesquisa, tendo em vista que aspectos positivos que poderiam ter sido evidenciados, não o foram, e os aspectos negativos foram os mais salientados.

Os autores Lourenço, Lemos e Junior (2012) trouxeram uma contribuição semelhante ao resultado desta pesquisa, provavelmente por encontrar as mesmas dificuldades que os alunos do curso de administração da UFMT - Câmpus de Rondonópolis encontram na realização do estágio, devido à falta de parcerias, da deficiência de suporte tanto da universidade, das empresas e do orientador.

A partir dos achados dessa pesquisa, cabe indicar algumas sugestões, como formas alternativas para realização do estágio. Uma alternativa seria que o aluno pudesse desenvolver os estágios dentro da própria 
universidade. Isso demandaria a elaboração de um programa de estágio cujo objetivo seria atender às necessidades de atividades de práticas dos ensinamentos colhidos na academia, possibilitando a efetiva participação do aluno, e a presença e disponibilidade do orientador em todas as fases; Outra opção está descrita na própria Lei de estágio $n^{\circ} 11.788$, no $3^{\circ}$ parágrafo do $2^{\circ}$ artigo, que estabelece que "as atividades de extensão, de monitorias e de iniciação científica na educação superior, realizadas pelo estudante, poderão ser equiparadas ao estágio, quando previsto no projeto pedagógico do curso" (BRASIL, 2008).

Esta pesquisa apresenta tanto contribuições teóricas, apresentando discussões para ampliar o conhecimento científico sobre o assunto, quanto contribuições práticas, pois, acredita-se que os resultados possam contribuir com o curso de administração da UFMT/CUR que atualmente se encontra em processo de transição para a adoção de um novo Projeto Pedagógico de Curso (PPC).

Finalmente, sugere-se uma reflexão ampla sobre as possibilidades de aprimoramento na operacionalização do processo do estágio supervisionado curricular obrigatório, no que tange aos itens já mencionados de maneira a propiciar uma interação harmoniosa entre as cinco categorias apresentadas nesta pesquisa, no tocante a parceria, obrigatoriedade, adequação, oportunidade e suporte contribuindo na formação do administrador.

Deste modo, como sugestões de estudos futuros, indica-se ampliar a pesquisa na intenção de verificar as percepções, concedendo voz aos professores orientadores de estágio supervisionado e às organizações que acolhem os estagiários, possibilitando um entendimento do fenômeno sob diferentes olhares.

\section{REFERÊNCIAS}

ALMEIDA, D. R.; LAGEMANN, L.; SOUSA, S. V. A. A importância do estágio supervisionado para a formação do administrador. In: ENCONTRO DA ASSOCIAÇÃO NACIONAL DE PÓS-GRADUAÇÃO E PESQUISA EM ADMINISTRAÇÃO, 30., 2006, Salvador. Anais... Salvador: AnPAD, 2006, p. 1-16.

AQUINO, R. D.; TOMASSINI, R. Os estágios curriculares e suas representações sociais segundo os graduandos em administração. In: ENCONTRO DA ASSOCIAÇÃO NACIONAL DE PÓS-GRADUAÇÃO E PESQUISA EM ADMINISTRAÇÃO, 32, 2008, Rio de Janeiro. Anais... Rio de Janeiro: AnPAD, 2008, p. 1-15.

BRASIL. Presidência da República - Casa Civil. Decreto-lei n 4.073, de 30 de janeiro de 1942. Disponível em: <http://www.planalto.gov.br/ccivil_03/decreto-lei/1937-1946/Del4073.htm>. Acesso em: 25 jun. 2016.

BRASIL. Presidência da República - Casa Civil. Lei n 11.788, de 25 de setembro de 2008. Disponível em: <http://www.planalto.gov.br/ccivil_03/_ato2007-2010/2008/lei//11788.htm>. Acesso em: 02 jul. 2016.

COLOMBO, I. M.; BALLÃO, C. M. Histórico e aplicação da legislação de estágio no Brasil. Educar em Revista, Curitiba, n. 53, p. 171-186, jul/set 2014.

FESTINALLI, R. C.; CANOPF, Liliane.; BERTUOL, Ornella. Estágio supervisionado em administração: reflexões de sua contribuição para a formação profissional. Revista Faz Ciência, v. 9, n. 9, p. 299-322, jan/jun 2007.

FREY, M. R.; FREY, I. A. A contribuição do estágio supervisionado na formação do bacharel em ciências contábeis. Revista contabilidade vista e revista. Belo Horizonte, v. 13, n. 1, p. 93-104, abril 2002.

IEL. Instituto Euvaldo Lodi. Lei de Estágio: tudo o que você precisa saber. Brasília - DF. 2010.

LOURENÇO, M. L.; LEMOS, I. S.; PÉCORA JUNIOR, J. E. Desafios e possibilidades no estágio supervisionado obrigatório: a visão dos estudantes do Curso de Administração. Revista administração: ensino e pesquisa. Rio de Janeiro, v. 13, n. 3, p. 559-596, jul/ago/set 2012.

MAÇANEIRO, M. B. Estágio curricular supervisionado: uma proposta ao curso de secretariado executivo. Revista capital científico. Paraná, v. 2, n. 1, p. 97-108 jan/dez 2004.

MELLO E CASTRO, L. A. M. H.; NISHIMURA, A. T.; SILVA, C. M.; CASADO, T.; MADUREIRA, B. M. Expectativas e satisfação dos alunos de graduação em Administração da FEA-USP/SP em relação aos estágios. Revista de Gestão. São Paulo, v. 14, n. especial, p. 61-76, 2007. 
MICHELS, Expedito. O papel do estágio supervisionado e a contribuição do trabalho de conclusão de curso para a formação de profissionais de administração: um estudo de caso. Florianópolis, 2012. 146 f. Dissertação (mestrado) Universidade Federal de Santa Catarina, Centro Socioeconômico. Programa de Pós-Graduação em Administração Universitária.

MINTZBERG, Henry.; GOSLING, Jonathan. Educando administradores além das fronteiras. Revista de Administração de Empresas. São Paulo, v. 43, n. 2, p. 29-43, abr/maio/jun 2003.

MURARI, J. M. F.; HELAL, D. H. O estágio e a formação de competências profissionais em estudantes de administração. Revista Gestão e Planejamento. Salvador, v. 10, n. 2, p. 262-280, jul/dez 2009.

NASCIMENTO, L. C.; TEODÓSIO, A. S. S. O estágio diante dos desafios do ensino em administração: um estudo de caso sobre as percepções de alunos e supervisores. In: ENCONTRO DA ASSOCIAÇÃO NACIONAL DE PÓSGRADUAÇÃO E PESQUISA EM ADMINISTRAÇÃO, 29, 2005, Brasília. Anais... Brasília: AnPAD, 2005, p. 1-15.

NICOLINI, Alexandre. Qual será o futuro das fábricas de administradores. Revista de Administração de Empresas. Salvador, v. 43, n 2, p. 44-54, abr/maio/jun 2003.

RAIA, F. S.; MELZ, L. J. Percepção dos discentes e docentes sobre estágio supervisionado no curso de ciências contábeis da UNEMAT - campus de Tangará da Serra. Revista Contemporânea de Contabilidade. Florianópolis, v. 8, n. 16, p. 111-136, jul/dez 2011.

ROESCH, S. M. A. Projetos de estágio e de pesquisa em administração: guia para estágios, trabalhos de conclusão, dissertações e estudos de caso. 2. ed. São Paulo: Atlas, 1999.

SANTOS, R. A.; SCHMIDT, A. O. A importância do estágio para a formação profissional e o acesso ao mercado de trabalho. In: VII SEMINÁRIO DO CENTRO DE CIÊNCIAS SOCIAIS APLICADAS. Cascavel, 2008. Anais... Disponível em: <http://www.unioeste.br/campi/cascavel/ccsa/VIISeminario/administracao/artigo15.pdf> Acesso em 10 fev. 2017. 